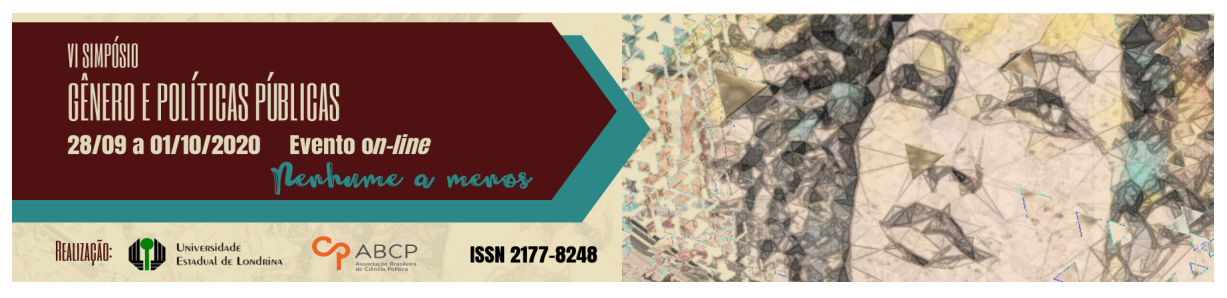

\title{
O Poder Judiciário brasileiro e a importância da diversidade de gênero para a tomada de decisões democráticas
}

\author{
Letícia de Souza Baddauy ${ }^{1}$; Carolina Malvezzi Garcia ${ }^{2}$
}

\section{Resumo}

O presente trabalho visa a analisar a importância da diversidade de gênero para a tomada de decisões judiciais mais democráticas nos Tribunais brasileiros, tendo como objetivo entender como as heurísticas e vieses influenciam na tomada de decisões pelos magistrados, especificamente nos Tribunais Regionais Federais Brasileiros, que são 5 ao todo e constituídos majoritariamente por homens. Partindo-se do contexto histórico de desigualdade de gênero que sempre existiu no Brasil, buscou-se analisar os resultados obtidos através de pesquisa bibliográfica, que demonstram que, em razão da sociedade atual ter sido sabidamente construída a partir da dominação masculina, os Tribunais brasileiros ainda estão longe de serem ocupados equitativamente por mulheres e homens, além do fato de haver inúmeras heurísticas e vieses que influenciam as decisões judiciais e as tornam sexistas.

Palavras-chave: diversidade de gênero; heurísticas e vieses; poder judiciário.

\section{The brazilian judiciary and the importance of gender diversity for democratic decision-making}

\section{Abstract}

The present work aims to analyze the importance of gender diversity for making more democratic judicial decisions in Brazilian courts, aiming to understand what are the main factors that keep women away from the rise in the career of the judiciary, since, currently, the majority of Brazilian magistrates

\footnotetext{
${ }^{1}$ Mestre em Direito Negocial, área Processo Civil/UEL. Graduada em Direito pela Faculdade de Direito da Universidade de São de Paulo - USP. Advogada. Professora/UEL. leticia@uel.br.

2 Pós-graduanda em Processo Civil pelo Instituto de Direito Constitucional e Cidadania - IDCC, 2020/2021. Pós-graduada em Direito Tributário. Graduada em Direito pela Pontifícia Universidade Católica do Paraná - PUCPR. Advogada. carolinamalvezzi@hotmail.com.br
}

GT 13 - Gênero, participação e representação política 
who make up the Courts are male, besides understanding the influences in the decisions that such a scenario can entail. Starting from the historical context of gender inequality that has always existed in Brazil, we sought to analyze the results obtained through bibliographic research, which demonstrate that, because the current society has been known to have been constructed from male domination, the Brazilian courts are still far from being occupied equitably by women and men, besides the fact that there are numerous heuristics and biases that influence judicial decisions and make them sexist.

Keywords: gender diversity; heuristics and biases; judiciary.

\section{Sumário}

1. Introdução; 2. Contexto Histórico da Desigualdade de Gênero; 3. Heurísticas e Vieses - o processo decisório; 3.1. Ancoragem; 3.2. Disponibilidade e afeto; 3.3. Representatividade; 3.4. Vieses; 4. O Poder Judiciário brasileiro e a importância da diversidade de gênero para a tomada de decisões democráticas; 5 . Conclusão. Referências.

\section{Introdução}

O presente artigo tem como principal foco de estudo e análise a presença das mulheres magistradas nos Tribunais brasileiros, especificamente nos Tribunais Regionais Federais do Brasil, que são cinco, e como as heurísticas e vieses podem influenciar e influenciam nas decisões e julgamentos colegiados, para concluir, ao final, a importância da diversidade de gênero para a tomada de decisões judiciais democráticas.

Partindo-se de um contexto histórico sobre a reconhecida desigualdade de gênero na sociedade, será feita uma linha do tempo em relação à hierarquização sexual e histórico da dominação masculina ao longo do tempo, abordando-se conceitos e em quais mecanismos enraizados na sociedade a desigualdade se mantém em todas as instituições atuais, em menor ou maior grau.

Sabidamente, a mulher conquistou recentemente direitos que há muito já eram dos homens, sendo que até os dias atuais é atingida e prejudicada por séculos de desigualdade de gênero que ainda são perpetuadas. Ademais, é fato notório que a mulher ainda não é 
remunerada em igualdade de condições com os homens e que sofre diversos preconceitos no mercado de trabalho pelo fato de ser mãe ou de querer ser.

A partir desse contexto histórico de desigualdade, o segundo capítulo faz uma abordagem conceitual sobre as heurísticas e vieses, explicando como influenciam na tomada de decisão pelos indivíduos, já que as heurísticas constituem atalhos mentais que são utilizados pelo ser humano no momento da tomada de decisões, que tendem a simplificar a questão e facilitar o processo decisório. Os vieses são erros que decorrem da aplicação das heurísticas, pois acabam limitando ou distorcendo a capacidade dos indivíduos de tomarem decisões.

Conforme será demonstrado, são três as heurísticas (disponibilidade, representatividade e ancoragem) que influenciam na tomada de decisões e delas decorrem diversos vieses possíveis.

O terceiro e último capítulo abordará, através de números dos Tribunais Regionais Federais, como a desigualdade de gênero está presente nesses espaços, que contam com percentual muito baixo (ou nenhum, como o caso do Tribunal Regional Federal da Quinta Região) de mulheres desembargadoras, demonstrando como as heurísticas e vieses em um ambiente tão homogêneo como os Tribunais brasileiros podem acarretar decisões sexistas e enviesadas, o que se deve, em parte, ao fato de que tais percepções são, muitas vezes, compartilhadas pela população, de forma que parecem naturais e corretas, e são reproduzidas pelo Poder Judiciário, que absorve tal realidade de maneira inconsciente por também ser resultado de uma construção comportamental patriarcal.

Como resultado, chegou-se à conclusão/proposição de que as decisões são prolatadas com base em noções pré-existentes dos papéis sexuais, podendo-se dizer que os julgamentos acabam comprometidos, por serem um reflexo parcial da realidade/sociedade. Portanto, para que sejam tomadas decisões mais democráticas nos Tribunais, é preciso que as decisões judiciais passem a ser tomadas através de órgãos mais 
heterogêneo e pluralistas, aptos, assim, a contribuir para a neutralização das heurísticas e vieses presentes em todos os seres humanos.

\section{Contexto histórico da desigualdade de gênero}

Diversos teóricos, ao longo do tempo, desenvolveram estudos e uma construção histórica sobre a desigualdade de gênero na sociedade, construção essa que, indubitavelmente, parte de um sistema de desigualdade negativa, de hierarquização sexual, já que se sabe que há uma sobreposição de gênero, com histórico de dominação masculina sobre a feminina.

Essa sobreposição de gênero, observada em diversas culturas e em diversos países, em maior ou menor grau, não havendo consenso sobre o momento do seu surgimento, é denominada patriarcado e resultou, ao longo do tempo, em uma diferenciação percebida até os dias atuais, tanto econômica quanto política, teorizada (pelos homens) a partir das diferenças biológicas e por meio de mecanismos que tinham a finalidade de dominação de um gênero pelo outro.

Em “A dominação masculina”, Pierre Bordieu (2012, p. 17) explica que a divisão entre os sexos está de tal forma enraizada que parece estar "na ordem das coisas":

A divisão entre os sexos parece estar "na ordem das coisas", como se diz por vezes para falar do que é normal, natural, a ponto de ser inevitável: ela está presente, ao mesmo tempo, em estado objetivado nas coisas (na casa, por exemplo, cujas partes são todas "sexuadas"), em todo o mundo social e, em estado incorporado, nos corpos e nos habitus dos agentes, funcionando como sistemas de esquemas de percepção, de pensamento e de ação.

Para o autor, a concordância com as estruturas objetivas e cognitivas faz com que a apreensão do mundo social e de suas arbitrárias divisões seja natural ao indivíduo, até por não perceberem os profundos mecanismos de dominação enraizados na sociedade, legitimando, assim, a divisão entre os sexos, de forma mais ou menos 
consciente e intencional.

Bordieu (2012, p. 18) ainda detalha o fato de que a dominação masculina é vista sem necessidade de legitimação, em razão de estar deveras mascarada nas relações e estruturas sociais, ou seja, que a construção da visão androcêntrica não precisa ser legitimada, pois foi concebida pelas diversas sociedades e imposta de forma neutra e natural ao longo do tempo.

Saffioti (2011, p. 44/45), em "Gênero, patriarcado, violência”, traz uma definição de gênero, aduzindo que o mesmo não explicita, necessariamente, uma desigualdade entre homens e mulheres, mas pode ser definido, apesar de não haver consenso sobre tal definição, como sendo a "construção social do masculino e do feminino".

A autora ainda traz uma definição do que entende como patriarcado, sendo, como o próprio nome indica, o regime de dominação-exploração das mulheres pelos homens, que não abrange apenas a família, mas está presente em todas as instituições sociais, afirmando ainda que este pode ser entendido como uma categoria específica que se refere a milênios da história mais próxima, nas quais se implantou uma hierarquia entre homens e mulheres, com primazia masculina, enquanto que o gênero seria uma categoria geral, em razão da definição dada no parágrafo acima.

Simone de Beauvoir, escritora, feminista, teórica social, em “O segundo sexo I - Fatos e Mitos", construiu reflexão sobre como e por quais meios, à luz da liberdade individual, o ser humano pode se realizar dentro da condição feminina e, em trecho de seu livro, partindose da questão da submissão da mulher e de onde ela vem, faz comparação entre a condição da mulher e dos proletários, aduzindo que estes, ao contrário das mulheres, se reúnem em uma unidade para se oporem à opressão a que são submetidos, em torno de uma solidariedade de trabalho e interesses, podendo, inclusive, através da união de forças, derrubar a classe dirigente; enquanto as mulheres não possuem tal similaridade de relacionamento entre si ou o desejo/poder comum de derrubar o homem (fazendo a analogia com o proletariado). 
Complementando seu brilhante entendimento, a autora (BEAUVOIR, 1970, p. 13) ainda afirma que "a divisão dos sexos é, com efeito, um dado biológico e não um momento da história", o que explicaria a perpetuação da desigualdade de gênero observada até os dias atuais.

Importante compreender o fato de que o patriarcado e a ideologia dominante de inferioridade feminina foram forjados historicamente para serem encarados como naturais e construídos de forma a legitimar, sem serem necessárias maiores justificativas, as relações de poder e as diferenças entre os gêneros, que decorrem da estereotipação de sujeitos.

Saffioti (2011, p. 76-7) ainda faz uma importante ligação desse fato com a questão dos direitos humanos, que desde a Revolução Francesa foram pensados no masculino, sendo que Olympe de Gouges foi sentenciada à morte na guilhotina, em 1792, por haver escrito a versão feminina dos direitos humanos (Declaração Universal dos Direitos da Mulher e da Cidadã).

Ademais, para Bordieu (2012, p. 32-3), a incorporação da dominação está no paradoxo de que são as diferenças visíveis entre o corpo feminino e o corpo masculino que, sendo percebidas e construídas segundo a visão androcêntrica, causam uma hierarquização social.

Desde os primórdios, portanto, a identidade masculina era sobrepujada à das mulheres, à medida em que o homem era reconhecido pela sua virilidade, tanto no que se refere ao porte físico, como em questões que estavam interligadas a honra e ética.

Pode-se dizer que a submissão feminina sobre a dominação masculina que trata Bordieu também encontra embasamento em outros teóricos, como Simone de Beauvoir, a qual afirma que a mulher não nasce mulher, torna-se mulher (BEAUVOIR, 1967, p. 9). Tal construção deve-se pautar em uma classificação e, sobretudo, ocultação dos mecanismos básicos de diferenciação que se tem perpetuado com o passar dos tempos. 
A partir de tal conceituação da desigualdade de gênero, assim como do patriarcado, pode-se afirmar que os diversos elementos ocultos de dominação masculina são mantidos em diversas instituições, tais como Estado, família, mercado de trabalho, entre outros, através da replicação de atitudes, expressões e rituais de subjugação da mulher.

Apesar de ter-se conhecimento de que as mulheres já vinham promovendo discussões sobre a desigualdade de gênero e dominação masculina, foi a partir da Revolução Francesa que buscaram discutir e desconstruir os padrões de dominação prioritariamente masculina, abertura que adveio da ampliação da liberdade econômica, surgindo, assim, movimentos pelos quais as mulheres buscavam a concretização de direitos que já eram concedidos, há muito tempo, aos homens.

A mudança de paradigma em relação às mulheres e, posteriormente, a elevação à condição de sujeito de direito transformaram-nas em merecedoras de proteção de direito humanos e iniciaram um processo de equalização social, ofertando um panorama e os efeitos sociais da precária e tardia inserção digna das mulheres na esfera pública, reconhecidamente mais tardia para mulheres negras do que para brancas.

Piovesan (2009, p. 02) traça uma retrospectiva histórica de movimentos que aconteceram no Brasil: surgimento da primeira lei sobre educação das mulheres, permitindo que frequentassem as escolas elementares (1827); a autorização do Governo para estudarem em instituições de ensino superior (1879); o Código Eleitoral admite o voto das mulheres (1932); a promulgação da Lei $n^{\circ} 4.121 / 1962$, que alterou disposições do Código Civil de 1916 e retirou as mulheres casadas do rol de pessoas relativamente incapazes para prática de determinados atos da vida civil (1962) e, como marco teórico da igualdade entre os gêneros, a Constituição Federal garante a igualdade de direitos e obrigações entre homens e mulheres perante a lei (1988).

Através de importantes marcos históricos, é possível afirmar também que a mulher vem ocupando cada vez mais espaços no meio jurídico, apesar deste ainda se mostrar uma vertente conservadora, que 
afeta as mulheres que atuam neste âmbito, como para as mulheres advogadas, que a duro custo vêm conquistando respeito e espaço (vide o exemplo da advogada Myrthes Gomes de Campos, primeira mulher no Brasil a exercer a profissão de advogada, que concluiu o bacharelado em Direito em 1898, mas em razão das discriminações que sofreu, conseguiu exercer a advocacia apenas em 1906) (MIGALHAS, 2015).

Apesar de na advocacia já ser possível observar um crescente número de mulheres exercendo a profissão, não se pode dizer o mesmo em relação à docência e, nessa perspectiva, tem-se o afirmado por Bonelli (2019, p. 663): “A inclusão das mulheres e da diferença na docência ganhou expressão recentemente, mas elas têm que lidar com a ideologia profissional dominante, apoiada no ideário da neutralidade do conhecimento, construído por homens, brancos, heterossexuais, dos grupos estabelecidos, a partir de perspectivas eurocêntricas".

E se a própria formação acadêmica do profissional reproduz o machismo social enraizado, é certo que esta realidade continuará a prosperar até que chegue - e por consequência influencie - as decisões dos magistrados.

Em relação à magistratura e, principalmente, aos mais latos cargos do Poder Judiciário, que são, majoritariamente, ocupados por homens e, partindo-se da premissa de que o ser humano é resultado de toda a sua construção social, além do fato de que a vivência de tal processo é apreendida de formas distintas entre homens e mulheres, pode-se dizer que a tomada de decisões acaba prejudicada em um ambiente tão homogêneo quanto o jurídico/judiciário. Por tal motivo, é preciso que se estabeleça a relação entre as heurísticas e vieses e a tomada de decisões nas carreiras jurídicas.

\section{Heurísticas e vieses - o processo decisório}

Para que se possa compreender como as heurísticas e vieses influenciam na tomada de decisões nas carreiras jurídicas, é preciso que se compreenda seus conceitos. 
Hebert Simon (SIMON, 1957, p. 103) dedicou seus estudos e construiu um modelo explicativo do processo cognitivo humano, combinando determinantes externos e internos na sua compreensão, que é identificado pelo filósofo como atividade de resolução de problemas, sendo que a racionalidade é interpretada, para o autor, como racionalidade limitada e adaptativa. Neste contexto, aduz a necessidade de que dois aspectos sejam observados na tomada de decisões: a criatividade, que seria a capacidade do indivíduo de pensar além daquilo que lhe é apresentado, desvinculando-se de suas percepções psicológicas, para que seja possível vislumbrar outras inúmeras hipóteses que possam ser empregadas na tomada de decisão, e a intuição, que nada mais é do que a percepção pelo indivíduo de todas as experiências que acumula em sua vivência e que também acabam influenciando na tomada de decisões.

De maneira diferente, mas complementar, Daniel Kahneman (Prêmio Nobel de Economia) escreveu o livro "Rápido e Devagar: duas formas de pensar", além de outros artigos, que traduzem o entendimento do autor sobre o julgamento e a tomada de decisões, que foi moldado nos anos de sua pesquisa pelas descobertas no campo da psicologia, a partir de um estudo desenvolvido com o Psicólogo Cognitivo Amos Tversky. Diferentemente de Hebert Simon, estes autores usam da irracionalidade para explicar os processos cognitivos, modelo que será explorado neste artigo.

Para Kahneman (2012, p. 127) a definição técnica de heurística é: "um procedimento simples que ajuda a encontrar respostas adequadas, ainda que geralmente imperfeitas, para perguntas difíceis. A palavra tem a mesma raiz que heureca". Ou seja, são estratégias criadas que conduzem os indivíduos no momento da tomada de decisão ou um método de investigação com base na aproximação progressiva de um problema, de modo que cada etapa é considerada provisória.

Na obra acima citada, o autor aduz o fato de que os seres humanos possuem dois sistemas de julgamento e escolha, que chama de Sistema 1, "que opera automática e rapidamente, com pouco ou 
nenhum esforço e nenhuma percepção de controle voluntário", revelando uma tendência do ser humano de confiar em vez de duvidar, e Sistema 2, que "aloca atenção às atividades mentais laboriosas que o requisitam, incluindo cálculos complexos. As operações do Sistema 2 são muitas vezes associadas com a experiência subjetiva de atividade, escolha e concentração" (KAHNEMAN, 2012, p. 29).

Partindo-se para o conceito dos vieses - termo usado no âmbito da estatística e da psicologia cognitiva para expressar tendenciosidade, preconceito, tendência, propensão, inclinação, erro sistemático - ensina Sternberg (2008, p. 128) que estes são gerados a partir da utilização das heurísticas e acabam distorcendo e impossibilitando que o indivíduo pense de forma racional, vez que os vieses constituem-se em uma forma de irracionalidade na tomada de decisão, provocados pela confiança na heurística.

Em conformidade com o estudo desenvolvido por Kahneman e Tversky (2012, p. 524), Robbins (2000, p.74) dispõe sobre como as heurísticas influenciam na tomada de decisões dos seres humanos, ou seja, como utilizam-se de mecanismos simplificadores de soluções para problemas difíceis que enfrentam, o que faz com que as soluções sejam encaradas e aceitas como suficientemente boas, sem que se empreenda qualquer esforço na busca por respostas analíticas, se acomodando naquela que lhe pareceu conveniente.

Tais conceitos influenciam e se conectam com a temática do presente artigo, uma vez que se busca demonstrar que a diversidade de gênero nos Tribunais brasileiros é de suma importância para a tomada de decisões mais democráticas, já que há diversas heurísticas e vieses que tornam as decisões sexistas, pois majoritariamente tomadas por homens.

Kahneman não nega o fato de que tais heurísticas são totalmente úteis, "mas as vezes levam a erros graves e sistemáticos" (KAHNEMAN, 2012, p. 19), e para ele são três as heurísticas que influenciam os indivíduos na tomada de decisões: a de ancoragem, a de disponibilidade e afeto e a da representatividade, que serão aqui 
explicadas individualmente.

\section{Ancoragem}

A heurística da ancoragem (KAHNEMAN, 2012, p. 152-163) pode ser definida como aquela na qual se cria um atalho mental no momento da tomada de decisões, em que o cérebro se "ancora", muitas vezes de maneira inconsciente, em um número ou uma informação no momento do julgamento, ocorrendo uma ativação associativa que determina/influência na decisão tomada.

Segue exemplo de um experimento realizado pelo autor que se amolda à conclusão do presente artigo (KAHNEMAN, 2012, p. 160):

O poder de ancoras aleatórias foi demonstrado de algumas maneiras preocupantes. Juízes alemães com uma média de mais de 15 anos de experiência em tribunal primeiro liam a descrição de uma mulher que fora detida por um furto em lojas, depois lançavam dois dados que haviam sido adulterados de modo a dar sempre 3 ou 9. Assim que os dados paravam de se mover, perguntava-se aos juízes se iriam sentenciar a mulher a uma pena de prisão maior ou menor, em meses, do que o número apresentado no dado. Finalmente, os juízes eram instruídos a especificar a exata sentença de prisão que dariam à mulher. Em média, os que haviam rolado um 9 diziam que iriam sentenciá-la a oito meses; os que obtinham um 3 diziam que iriam sentenciá-la a cinco meses; o efeito de ancoragem foi de $50 \%$.

A conclusão a que o autor chegou é que muitas decisões/julgamentos são influenciados por um número ou informação obviamente não informativo, e que há dois mecanismos diferentes que produzem o efeito de ancoragem: o ajuste - que opera dentro do Sistema 2, e o priming, que é uma manifestação automática do Sistema 1.

Utilizando-se o exemplo acima transcrito, sobre os juízes alemães, pode-se dizer que o mecanismo de ajuste ocorre quando, 
apresentado a um número aleatório, o indivíduo avalia se é alto ou baixo demais para a situação em que está inserido e gradualmente passa a ajustar uma estimativa, movendo-se mentalmente a partir da âncora, gerando, assim, quantidades incertas para um determinado dado aleatório fornecido.

Já o "efeito de priming" seria uma sugestão que evoca seletivamente evidência compatível, ou uma coerência associativa entre um dado informado sugestivamente com outros dados, formando uma associação de ideias, consciente ou inconscientemente.

Disso decorre que os efeitos do priming são a fonte que muitas vezes influenciam escolhas, ações e julgamentos de maneira intuitiva, que podem estar corretas ou não, e que tais influências, no pensamento e comportamento, acontecem pelo momento e pelo ambiente em que o indivíduo está inserido.

\section{Disponibilidade e afeto}

A heurística da disponibilidade é aquela em que os indivíduos/decisores avaliam determinada situação/problema que se coloca a sua frente a partir de suas próprias vivências, ou seja, define a probabilidade de um evento de acordo com informações de eventos passados e simulares que já aconteceram em sua vida.

Essa heurística é definida por Kahneman (2012, p. 165-6) como “o processo de julgar a frequência segundo a facilidade com que as ocorrências vêm à mente. (...) A heurística da disponibilidade, como outras heurísticas de julgamento, substitui uma questão por outra: você deseja estimar o tamanho de uma categoria ou a frequência de um evento, mas comunica uma impressão da facilidade com que as ocorrências vêm à mente".

Assim é que eventos dramáticos, experiências pessoais ou eventos vividos são mais facilmente acessados pelo cérebro do que incidentes que aconteceram com outras pessoas, estatísticas ou palavras. Significa dizer que um evento que tenha acontecido com um 
indivíduo irá afetá-lo mais do que qualquer evento que tenha acontecido com outra pessoa de que teve conhecimento.

Desta definição decorre o conceito de heurística do afeto, que dispõe que os julgamentos e as decisões que os indivíduos produzem acerca de variadas situações estão diretamente ligadas às suas emoções, ou seja, ao fazer um julgamento ou tomar uma decisão, as emoções são frequentemente consultadas, formando opiniões e fazendo escolhas que expressam diretamente seu sentimento, muitas vezes sem se dar conta de tal fato (KAHNEMAN, 2012, p. 177).

Assim, pode-se dizer que a heurística da disponibilidade e afeto traduz-se em um modelo eficaz e rápido na tomada de decisões em situações de incerteza, constituindo-se em uma forma comum de julgamento, mas que pode levar o indivíduo a equívocos e erros ao organizar e processar uma informação.

\section{Representatividade}

A heurística da representatividade é aquela que parte do pressuposto de que o indivíduo toma suas decisões através de estereótipos criados pela sua vivência, ou seja, ao se confrontar com determinado evento, este tenta encontrar similaridades com estereótipos apreendidos.

Nesse sentido, Tonetto et al assim aduzem sobre a heurística da representatividade: "é conferida alta probabilidade de ocorrência a um evento quando esse é típico ou representativo de um tipo de situação" (TONETTO et al, 2006, p. 186).

Tal heurística demonstra o fato de que os indivíduos não são bons estatísticos intuitivos e que julgamentos subjetivos são tendenciosos, já que, conforme dito, a heurística da representatividade é aquela em que os indivíduos usam estereótipos ao formularem julgamentos.

De acordo com os diversos experimentos empreendidos nessa 
linha, confirmou-se que os indivíduos tendem a ordenar, por exemplo, a ocupação de uma pessoa, por probabilidade ou similaridade, como num experimento feito (TVERSKY; KAHNEMAN, 2012, p. 525) sobre as características da personalidade de determinado agente, em que pelas suas características pessoais inferiu-se que o mesmo tinha a ocupação de bibliotecário e não de fazendeiro, quando, em verdade, é muito mais provável estatisticamente que as características sejam encontradas num fazendeiro, do que em um bibliotecário (o experimento foi realizado nos Estados Unidos da América).

Tal abordagem demonstra que há alguma verdade e previsões corretas nos estereótipos que guiam um julgamento de representatividade. Mas, embora útil em termos de economia cognitiva, pode produzir erros e distorções nos julgamentos, uma vez que a representatividade faz com que vários outros aspectos, como o estatístico, não sejam levados em conta, produzindo distorções e discriminações, que ocorrem quando há confiança exclusiva na heurística (KAHNEMAN, 2012, p. 195).

\section{Vieses}

Bazerman (1994, p. 56) melhor define os vieses decorrentes de tais heurísticas, aduzindo que os principais vieses emanados da heurística da disponibilidade, seriam: facilidade da lembrança, em que os indivíduos julgam de acordo com memórias recentes que mais facilmente vem à mente; capacidade de recuperação, em que os indivíduos são influenciados pela frequência de eventos e de como a memória busca por esses eventos.

Para a heurística da representatividade, expõe que decorrem os seguintes vieses: falta de sensibilidade à proporções da base, que é a característica dos indivíduos de ignorarem as proporções da base na apreciação da probabilidade de eventos, quando é fornecida qualquer outra informação descritiva, mesmo que irrelevante; falta de sensibilidade ao tamanho da amostra, que aduz que frequentemente os indivíduos não analisam o tamanho da amostra na avaliação da confiança de 
informações desta; concepções errôneas sobre o acaso, que significa dizer que os indivíduos esperam que dados gerados por um processo aleatório pareça aleatório, mesmo quando curto para representar uma estatística válida; regressão à média, que aduz que os indivíduos ignoram o fato de que situações extremas tendem a regredir à média em ocasiões/tentativas subsequentes; e falácia da conjunção, que é aquela em que os indivíduos julgam erroneamente que dois eventos que acontecem em conjunto são mais prováveis do que um conjunto mais global de ocorrências, do qual os eventos conjuntos são uma subespécie.

No caso da heurística da ancoragem, os seguintes vieses: insuficiente ajustamento da âncora, que ocorre quando estimativas são feitas a partir de um valor e o julgamento é produzido a partir de um insuficiente ajuste daquela âncora (valor inicial); viés de eventos conjuntivos e disjuntivos, que caracteriza os julgamentos que são feitos tendendo para uma superestimação da probabilidade de eventos conjuntivos e subestimação da probabilidade de eventos disjuntivos; e excesso de confiança, que é o viés que explica que os indivíduos tendem a serem confiantes quanto à infabilidade de seus julgamentos, quando deparados com perguntas de dificuldade moderada a extrema.

Além disso, Bazerman (1994, p. 57) apresenta dois vieses que emanam da combinação do uso de mais de uma heurística, que seriam: armadilha da confirmação e retrospecto. No caso do viés da armadilha da confirmação, o indivíduo tende a buscar informações que confirmem aquilo que consideram verdadeiro, negligenciando a busca de informações que a invalidem. Já o viés do retrospecto é aquele em que há uma superestimação pelo indivíduo do grau que teria antevisto o resultado correto após observarem a ocorrência ou não de um evento.

Aplicando-se os ensinamentos de Tversky e Kahneman (2012, p. 524) e Bazerman (1994) à temática do presente artigo, é de se considerar que para haver uma interpretação jurídica confiável, é necessário que o indivíduo reconheça a existência dessas heurísticas e dos vieses que elas produzem, para que se mantenham atentos aos erros sistemáticos que elas podem causar na tomada de decisões. 
Ademais, é possível afirmar que são inúmeros os gatilhos produzidos pelo ser humano que podem influenciar em seus julgamentos, de maneira consciente ou inconsciente, inclusive na discriminação que é conhecidamente recorrente em relação ao gênero. Ainda, considerando-se a desigualdade de gênero que é verificada nos Tribunais brasileiros, que contam majoritariamente com juízes homens, bem como a quantidade de processos judiciais em trâmites, é possível afirmar também que muitos julgamentos são produzidos de forma sexista, em que o decisor é influenciado por suas vivências e pela agilidade que o processo demanda, que o leva a produzir raciocínio simples e rápido, sem se atentar aos vieses, o que, por certo, produz discriminações e decisões errôneas.

\section{O Poder Judiciário brasileiro e a importância da diversidade de gênero para a tomada de decisões democráticas}

Conforme informações e estudos apresentados no Capítulo 1 deste artigo, em que restou conceituada e explicada a desigualdade de gênero, há diversos elementos ocultos de dominação masculina que são mantidas em instituições, como Estado, família, mercado de trabalho e, especificamente aqui, no Poder Judiciário brasileiro.

Em relação à advocacia, o número de mulheres registradas atualmente na Ordem dos Advogados do Brasil (OAB) alcança patamar de igualdade aos homens, são 558 mil homens e 524 mil mulheres (CONSELHO FEDERAL DA OAB, 2020, n.p). Mas a inserção da mulher na advocacia é recente, considerando o exemplo já dado da primeira mulher a exercer a profissão no Brasil, Myrthes Gomes de Campos, que se formou em 1898, mas só conseguiu atuar legitimamente em 1906 (MIGALHAS, 2015).

O crescente número de mulheres na advocacia não se reflete no número de magistradas atuantes nos Tribunais brasileiros. As principais dificuldades e formas de restrição de participação e ascensão hierárquica profissional ficam demonstradas a partir de uma pesquisa realizada pela Associação dos Juízes Federais do Brasil (AJUFE), em que 
se traça o perfil da presença feminina de acordo com os Tribunais Regionais Federais brasileiros, que são cinco ao todo.

O Tribunal Regional Federal da Primeira Região é composto pelo Distrito Federal e por treze estados brasileiros, sendo que compõem o quadro de desembargadores cinco mulheres e vinte e um homens (dado obtido a partir do site oficial do Tribunal Regional Federal da Primeira Região). Ou seja, o Tribunal é composto 80,7\% por homens e $19,3 \%$ por mulheres.

O Tribunal Regional Federal da Segunda Região possui competência sobre o Espírito Santo e o Rio de Janeiro e tem no quadro de desembargadores vinte e dois homens e cinco mulheres. Ou seja, o Tribunal é composto $81,5 \%$ por homens e 18,5 por mulheres (dado obtido a partir do site oficial do Tribunal Regional Federal da Segunda Região).

No que diz respeito ao Tribunal Regional Federal da Terceira Região, tem-se o englobamento dos estados de São Paulo e Mato Grosso do Sul, sendo que trinta e três desembargadores homens compõem o tribunal e nove mulheres (dado obtido a partir do site oficial do Tribunal Regional Federal da Terceira Região). Ou seja, o Tribunal é composto $78,5 \%$ por homens e $21,5 \%$ por mulheres.

De acordo com a Divisão de Assuntos da Magistratura (DMAG), desde o ano de 1989, o Tribunal Regional Federal da Terceira Região contou com o quadro de 26 desembargadoras e 57 desembargadores, estes últimos em quantidade maior que o dobro em relação as mulheres.

O Tribunal Regional Federal da Quarta Região possui sede em Porto Alegre e é composto pelos estados do Paraná, Santa Catarina e Rio Grande do Sul, contando com um total de vinte e oito desembargadores, dentre os quais dezenove são homens e oito são mulheres (dado obtido a partir do site oficial do Tribunal Regional Federal da Quarta Região). Ou seja, o Tribunal é composto $67,8 \%$ por homens e $32,2 \%$ por mulheres.

Ainda, de acordo com os dados fornecidos pelo Tribunal, ao nos referirmos a promoção por merecimento, uma relevante discrepância se 
impõe: trinta e seis homens e apenas duas mulheres. Aqui a diferença comprova que quanto maior a hierarquia presente no cargo, menos cadeiras são ocupadas por mulheres.

O Tribunal Regional Federal da Quinta Região diz respeito aos estados de Pernambuco, Ceará, Rio Grande do Norte, Paraíba, Alagoas e Sergipe, e conta quinze desembargadores, sendo o Tribunal em que se mais constata a desigualdade de gênero, já que não há nenhuma mulher desembargadora (dado obtido a partir do site oficial do Tribunal Regional Federal da Quinta Região).

Diante de tais dados, que reportam ao ano corrente, verifica-se a desigualdade de gênero nos Tribunais Regionais Federais brasileiros, e como notado por Souza (2011, n.p), a participação feminina nas primeiras instâncias é mais expressiva, mas observa-se o seu distanciamento da cúpula do Poder Judiciário.

Partindo-se da premissa de que o ser humano é resultado de toda a sua construção social e que homens e mulheres vivenciam tal processo de formas distintas, é possível afirmar, estabelecendo-se uma relação entre os dados acima e as heurísticas e vieses demonstrados no Capítulo 2, que a tomada de decisões em um ambiente tão homogêneo quanto o verificado nos Tribunais Regionais Federais refletem a desigualdade de gênero existente, resultando em decisões fundadas em noções pré-existentes dos papeis sexuais (ROUND, 1998, p. 2193).

Em pesquisa e análise realizadas por Cristina Boyd, Lee Epstein e Andrew Martin (2010, p. 18), que procuraram possíveis diferenças entre decisões proferidas por magistrados e magistradas, restou demonstrado que juízas, em decisões monocráticas, tendem a julgar procedentes demandas cujos méritos são o reconhecimento de discriminação, em torno de $10 \%$ mais vezes que os juízes.

Grezzana (2011, p. 32) também realizou pesquisa a fim de verificar a existência de viés de gênero nos julgamentos realizados pelo Tribunal Superior do Trabalho (TST), analisando os impactos da composição de gênero das Turmas julgadoras e do sexo do Ministro Relator nos resultados das ações, tendo observado que Ministras 
tendiam a julgar mais vezes a favor de demandantes mulheres e Ministros tendiam a julgar mais vezes a favor de demandantes homens.

Ademais, tem-se o icônico estudo realizado por Danziger, Levav e Avnaim-Pesso cujo objetivo era testar o mote realista de que a justiça seria o que o juiz comeu no café da manhã. $O$ estudo, que visava os fatores que influenciavam na concessão de liberdade condicional na Suprema Corte americana, mostrou que a variável mais determinante era a proximidade em relação ao café da manhã e aos demais intervalos para refeição dos magistrados (DANZIGER; LEVAV; AVNAIM-PESSO, 2011).

Jolls e Sustein (2005, p. 10) propõem a criação de ações afirmativas que objetivem promover um ambiente mais heterogêneo nos Tribunais, de forma a neutralizar heurísticas e vieses que influenciam na tomada de decisões.

Assim, partindo-se do contexto histórico apresentado, de submissão da mulher em detrimento da dominação do homem ao longo dos últimos séculos, além da demonstrada existência e ocorrência de heurísticas e vieses nas decisões tomadas pelos seres humanos, é inequívoca a ocorrência de decisões sexistas nos Tribunais brasileiros, já que majoritariamente ocupado por homens.

\section{Conclusão}

A desigualdade de gênero é reconhecida e está presente na sociedade há muitos séculos, tanto que teve sua contextualização histórica exposta no primeiro capítulo deste artigo, em que restou demontrada uma linha do tempo em relação à hierarquização sexual e histórico de dominação masculina, que pode ser ainda encontrada, em menor ou maior grau, em diversas instituições, como Estado, família, mercado de trabalho.

Inegável o fato de que a mulher sofre diversas discriminações no mercado de trabalho, tanto por conta do acima exposto, como por uma subjugação de força e, ainda, por sua condição ou pretensão de mãe, 
além de outros diversos fatores que prejudicam a ascensão da mulher nas mais diversas carreiras e ainda diminuem os seus salários em comparação com os homens.

Uma sociedade democrática (e diz-se que estamos em um Estado Democrático de Direito), ou que, no mínimo, se pretende democrática, deve ser caracterizada, acima de tudo, como uma sociedade pluralista, em que diversos grupos sociais com interesses diferentes convivam sem que nenhum se sobresaia dominante.

No Brasil, pode-se afirma que a sociedade foi construída com bases sexista e machista e não se pode negar o fato de que tal realidade afeta e impacta diretamente num dos três poderes do Estado, o Poder Judiciário, tanto no que diz respeito à sua constituição, já que, em relação aos Tribunais Regionais Federais brasileiros, a diferença entre homens desembargadores e mulheres desembargadoras é discrepante (sendo majoritariamente ocupados por homens), tanto no que se refere às decisões produzidas em um cenário tão prejudicialmente homogêneo.

Essa construção histórica de desigualdade de gênero produz efeitos no Poder Judiciário, já que este está longe de ser ocupado equitativamente por mulheres e homens, além do fato de que restou demonstrado, por diversas pesquisas empíricas mencionadas ou não, que as heurísticas e os vieses impactam diretamente da tomada de decisões dos indivíduos, já que produzidas a partir de noções préexistentes dos papéis sexuais.

Ou seja, é necessário um espaço heterogêneo e pluralista para que sejam neutralizadas as heurísticas e os vieses presentes em todos os seres humanos, e para que, quando reunidos em torno de um julgamento, magistrados e magistradas possam debater e dar opiniões jurídicas diferentes, com base em construção social que reflita a diversidade presente no Brasil, em que todos conjuguem para o mesmo fim igualitário e de justiça. 


\section{Referências}

AJUFE, Associação dos Juízes Federais do Brasil. Nota técnica AJUFE Mulheres 02/2019. Brasília: 2019. Disponível em: https://www.ajufe.org.br/acoes- institucionais/notas-tecnicas. Acesso em: 20 jan. 2019.

BAZERMAN, M. Judgment in Managerial Decision Making. 3. ed. New York: Wiley, 1994.

BEAUVOIR, Simone de. O Segundo Sexo: A Experiência Vivida. Rio de Janeiro: Ed. Nova Fronteira, 1980.

BEAUVOIR, Simone de. O segundo sexo: Fatos e Mitos. v. 1. $4^{\mathrm{a}}$ ed. Tradução de Sérgio Milliet. São Paulo: Difusão Europeia do Livro, 1970.

BONELLI, Maria da Gloria. Magistradas brasileiras e sua prática profissional. Cadernos de Pesquisa, v. 47, n. 163, p. 94-120, 2017.

BOURDIEU, Pierre. A dominação masculina. Rio de Janeiro: Bertrand Brasil, 2007.

BOYD, Christina L.; EPSTEIN, Lee; MARTIN, Andrew D. Untanling the Causal Effects of Sex on Judging. American journal of political science, $\mathrm{v}$. 54, n. 2, p. 389-411, 2010.

DANZIGER, Shai; LEVAV, Jonathan; AVNAIM-PESSO, Liora. Extraneous factors in judicial decisions. Proceedings of the National Academy of Sciences of the United States of America (PNAS), v. 108, n. 17, 2011.

GREZZANA, Stefânia. Viés de gênero no Tribunal Superior do Trabalho brasileiro. 2011. Dissertação (Mestrado em Economia de Empresas) - FGV - Fundação Getúlio Vargas, São Paulo, 2011.

JOLLS, Christine; SUSTEIN, Cass R.. Debiasing through Law. Harvard Law and Economics, Discussion Paper n. 495, mar. 2005. Disponível em: http:/ /ssrn.com/abstract=590929. Acesso em: 10 dez. 2019.

KAHNEMAN, D. P.; SLOVIC, P.; TVERSKY, A. Judgment under Uncertainty: Heuristics and Biases. Cambridge: Cambridge University Press, 1988.

KAHNEMAN, D. Rápido e devagar: duas formas de pensar. Rio de Janeiro: Objetiva, 2012.

ORDEM DOS ADVOGADOS DO BRASIL OAB. Conselho Federal. 
Quadro de advogados quantitativo por gênero. Disponível em: https://www.oab.org.br/institucionalconselhofederal/quadroadvogado s. Acesso em: abr. 2019.

ORDEM DOS ADVOGADOS DO BRASIL. Dia da Mulher: conheça Myrthes Campos, a primeira advogada do Brasil. Migalhas. Atualizado em: 6 mar 2015. Disponível em: https://www.migalhas.com.br/Quentes/17,MI216736,31047-

Dia+da+Mulher+conheca+Myrthes+Campos+a+primeira+advogada+d o+Brasil. Acesso em: abr. 2019.

PIOVESAN, Flávia. Igualdade de Gênero na Constituição Federal: Os Direitos Civis e Políticos das Mulheres no Brasil. In: SENADO FEDERAL. Constituição de 1988: O Brasil 20 anos depois - Os Alicerces da Redemocratização. $\quad$ v. $1 . \quad$ Disponível em: https://www12.senado.leg.br/publicacoes/estudos-legislativos/tiposde-estudos/outras- publicacoes/volume-i-constituicao-de1988/principios-e-direitos-fundamentais-igualdade-de-genero-naconstituicao-federal-os-direitos-civis-e-politicos-das-mulheres-do-brasil. Acesso em: 03 out. 2019.

ROBBINS, S. P. Administração: mudanças e perspectivas. São Paulo: Saraiva, 2000.

ROUND, Deborah Ruble. Gender bias in the judicial system. Southern California Law Review, v. 61, n. 6, p. 2193-2220, 1998.

SAFFIOTI, Heleieth Iara Bongiovani. Gênero, patriarcado, violência. 2. reimp. São Paulo: Fundação Perseu Abramo, 2004.

SAFFIOTI, Heleieth Iara Bongiovani. O poder do macho. São Paulo: Moderna, 1987.

SIMON, Herbert. Models of Man, Social and Rational: Mathematical Essays on Rational Human Behavior in a Social Setting. New York: John Wiley and Son, 1957.

SOUSA, Ana Júlia da Silva de. Participação da mulher nos espaços de poder no Brasil: atuação feminina no executivo, legislativo e judiciário. Ambito Jurídico, Rio Grande, XIV, n. 91, ago. 2011.

STERNBERG, R. J.; Mio, J. S. Cognitive psychology. Wadsworth Publishing Company, 2008.

TONETTO, Leandro Miletto et al. O papel das heurísticas no julgamento 
e na tomada de decisão sob incerteza. Estudos de Psicologia, Campinas, v. 23, n. 2, p. 181- 189, jun. 2006.

TVERSKY, Amos; KAHNEMAN, Daniel. Julgamento sob incerteza: heurísticas e vieses. Apêndice A, p. 524-539. In: KAHNEMAN, Daniel. Rápido e devagar. Rio de Janeiro: Objetiva, 2012. 